\title{
CONSTRUCTAL ALKALINE MEMBRANE FUEL CELL (AMFC) DESIGN
}

\author{
E. M. Sommer ${ }^{a}$, J. V. C. Vargas ${ }^{a}$, L. S. Martins ${ }^{b}$ and J. C. Ordonez ${ }^{b *}$ \\ ${ }^{\text {a }}$ Department of Mechanical Engineering, Graduate Program in Mechanical Engineering, PGMEC, Federal \\ University of Paraná, UFPR, CP 19011, Curitiba, PR, CEP: 81531-980, Brazil \\ ${ }^{\mathrm{b}}$ Department of Mechanical Engineering, Energy Sustainability Center and Center for Advanced Power \\ Systems, Florida State University Tallahassee, Florida, 32310, USA
}

Email: jordonez@fsu.edu

\begin{abstract}
This paper introduces a structured procedure to optimize the internal structure (relative sizes, spacing) and external shape (aspect ratios) of a single alkaline membrane fuel cell so that net power is maximized. The optimization of flow geometry is conducted for the smallest (elemental) level of a fuel cell stack, i.e., the single alkaline membrane fuel cell, which is modeled as a unidirectional flow system. The polarization curve, total and net power, and efficiency are obtained as functions of temperature, pressure, electrolyte solution concentration $(\mathrm{KOH})$, geometry and operating parameters. The optimization is subjected to fixed total volume. There are two levels of optimization: (i) the internal structure, which basically accounts for the relative thicknesses of two reaction and diffusion layers and the membrane space, and (ii) the external shape, which accounts for the external aspect ratios of a square section plate that contains all single alkaline membrane fuel cell components. The available volume is distributed optimally through the system so that the net power is maximized. Temperature and pressure gradients play important roles, especially as the fuel and oxidant flow paths increase. The optimized internal structure and external shape are a result of an optimal balance between electrical power output and pumping power required to supply fuel and oxidant to the fuel cell through the gas channels. In the process, a third level of optimization was found with respect to the $\mathrm{KOH}$ concentration in the electrolyte solution that leads to a 3-way maximized net power output. The numerical results show that the maxima found are sharp, since a variation of up to $600 \%$ in net power was observed within the tested range of AMFC external aspect ratios, what emphasizes the importance of finding the optimal AMFC parameters, no matter how complex the actual design might be. It is also shown that the three times maximized net power increases monotonically with total volume raised to the power $0.7(\sim 3 / 4)$, similarly to metabolic rate and mass in animal design. Due to the fact that precision and low computational time are combined, it is expected that the model could be used as an important tool for AMFC design, control and optimization at the fuel cell stack level.
\end{abstract}

Keywords: Constructal AMFC, Internal structure, External shape, Electrolyte $\mathrm{KOH}$ mass fraction.

\section{INTRODUCTION}

Among the so called renewable energy technologies, fuel cells date back to the start of the nineteenth century [1], but require the use of hydrogen which is not naturally available in nature, thus economically effective $\mathrm{H} 2$ production methods should be developed in parallel. The most scientifically accepted classification of fuel cells is based on the type of electrolyte. Each definition is determined by the type and purity of the fuel, oxidant used, and the operating temperature. Accordingly, there are six main types of established fuel cells [2]: (i) Proton Exchange Membrane Fuel Cell (PEMFC); (ii) Alkaline Fuel Cell (AFC); (iii) Direct Methanol Fuel Cell (DMFC); (iv) Phosphoric Acid Fuel Cell (PAFC); (v) Molten Carbonate Fuel Cell (MCFC), and (vi) Solid Oxide Fuel Cell (SOFC). The first three are also classified as low temperature $\left(80-250^{\circ} \mathrm{C}\right)$, and the other three are medium to high temperature $\left(250-1000{ }^{\circ} \mathrm{C}\right)$. Currently, the low temperature PEMFC and the high temperature SOFC are considered the greatest promise for market commercialization [3-5]. However, Alkaline Fuel Cells (AFC) have interesting features as compared to polymer electrolyte fuel cells (PEMFC), such as higher current density, lower cost electrolyte ( $\mathrm{KOH}$ aqueous solution) and mainly, the possibility of using non-noble catalysts (e.g., nickel, silver), since faster kinetics of the reactions is observed in alkaline media than in acid media $[6,7]$.

Fuel cell optimization is a relatively new area of research since published articles on fuel cell optimization were practically non-existent before the year 2000 , and are singleobjective and multi-objective constrained optimization problems because these are the problems most commonly encountered in fuel cell design [8]. The optimization studies found in the literature are conducted for several levels: the single cell (components and entire cell), the stack, and a system with the stack and ancillary equipment (e.g., compressor, humidifier, cooler), and have mostly addressed the proton-exchange membrane fuel cell (PEMFC) [9].

As a result, this study is motivated by the need to develop a methodology that provides a structured process to synthesize fuel cell optimal thermodynamic configurations directly from the physical laws. The proposed technique seeks the general 
direction of flow geometry optimization subject to global constraints (e.g., volume), with the objective of maximizing the net power or the net power density. A possible path to follow could rely upon constructal theory [10], which is the thought that geometry (flow architecture) is generated by the pursuit of global performance subject to global constraints, in flow systems the geometry of which is free to vary. According to constructal theory, the optimization of flow architecture starts at the smallest (elemental) scale, in which the system still preserves its identity (e.g., a creek in a river basin; the single alkaline membrane fuel cell - AMFC in a fuel cell stack; a cell in a multi-cellular living organism). Irreversibilities due to all flow resistances (e.g., pressure drops, charge transfer, electrical resistances, mass diffusion) are minimized together for maximum global performance at the whole system level. Any physical system is a combination of several flow systems (e.g., electrical; chemical; fluid and heat flows). In sum, the thermodynamic optimization of flowsystem architecture is common in engineering and nature.

No AMFC optimization study was found in the literature that addresses the spatial temperature and pressure gradients in a single AMFC, pressure drops in the gas channels and their effect on performance. Therefore, the objectives of this paper are: i) to utilize a previously experimentally validated general (dimensionless) dynamic mathematical model [11] to analyze the physical response of a single AMFC, and ii) to optimize the internal and external structure, and electrolyte $\mathrm{KOH}$ concentration of a single AMFC for maximum net power. The fuel cell is divided into several control volumes that correspond to the most representative parts of the flow system [11]. All the flow phenomena that are present are taken into account. The result is a volume element model (VEM) $[12,13]$ with unidirectional internal flow that contains additional three-dimensional features such as the electrode wetted area, heat transfer between the cell, fuel, oxidant and the surroundings, and pressure drops in the gas channels. The approach is cross-disciplinary and pursues simultaneously: (i) the local optimization of components and processes with (ii) the optimal global integration and configuration of the system. A system of ordinary differential equations with respect to time delivers the temperatures of each control volume, from which, the resulting electrical and net power, first and second law efficiencies are computed as functions of time, to be able to analyze the system dynamic response. The model is simple enough to ensure small computational time requirements, so that it is possible to simulate the system steady state and transient response in a large number of competing geometric and operating configurations.

\section{MATHEMATICAL MODEL}

The dynamic mathematical model for the constructal design (thermodynamic optimization) of the single AMFC was introduced, adjusted and experimentally validated by Sommer et al. [11]. As a result of the model adjustment, empirical correlations were derived for expressing the dependence of the electrodes current density on the electrolyte $\mathrm{KOH}$ mass fraction, which are herein utilized to perform the single AMFC optimization.

A simplified modeling and simulation approach for energy systems engineering that is capable of providing quick and accurate responses during system design was utilized to write the single AMFC mathematical model namely a volume element model $[12,13]$. The fuel cell is divided into seven control volumes $(\mathrm{CV})$ that interact energetically with each other and with the environment as shown schematically in Fig. 1.

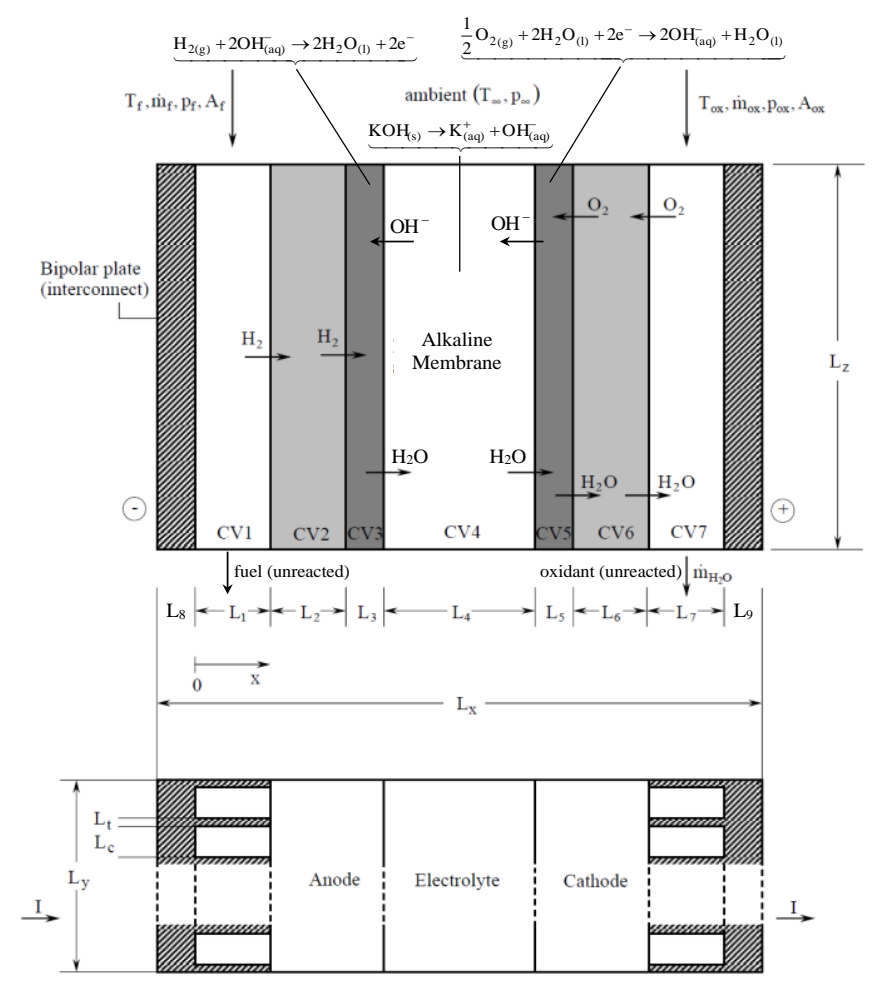

Figure 1. Schematic diagram of the AMFC internal and external structure [11]

The seven control volumes are: fuel channel (CV1), the anode diffusion layer (CV2), the anode reaction layer (CV3), the cellulose based alkaline membrane (CV4), the cathode reaction layer (CV5), the cathode diffusion layer (CV6) and the oxidant channel (CV7). Mass, energy and species conservation equations are written for each control volume, considering the chemical reactions on CV3 and CV5, which results on a time dependent unidirectional internal flow model. The heat generated by the electrochemical reactions and the potential losses are taken into account. The heat generation mechanisms are due to fuel cell ohmic resistances, activation and concentration overpotential losses in CV3 and CV5.

In fuel cell operation, the external load determines the operating current, therefore in this study the total cell current is considered the independent variable. Ordinary differential equations (ODEs) with respect to time and auxiliary algebraic equations yield temperature and pressure profiles for each control volume, and polarization and power curves of the system as well. The actual electrical potential and power are obtained by subtracting from the reversible potential the losses due to surface overpotentials (poor electrocatalysis), slow diffusion and and all internal ohmic losses through the cell. These are functions of cell voltage or of the total cell current (I), which have a one-to-one relationship with each other.

For all details of the mathematical model, including the definition of all variables, the reader is directed to consult the work of Sommer et al. [11]. 


\section{CONSTRUCTAL DESIGN}

According to Fig. 1, $L_{x}$ is the total length of the fuel cell (flow direction), ${ }^{L_{j}}$ the length of each control volume of the single AMFC, such that $1 \leq j \geq 7 . L_{y}$ and $L_{z}$ are the height and the thickness, respectively.

The total volume of the fuel cell, $V_{T}=L_{x} L_{y} L_{z}$, is finite and fixed, which is taken as a realistic design constraint, which accounts for the finiteness of the available space. The fixed length scale $V_{T}^{1 / 3}$ is used for the purpose of nondimensionalizing all the lengths that characterize the fuel cell geometry, as follows:

$$
\xi_{j}=\frac{L_{j}}{V_{T}^{1 / 3}}
$$

where the subscript $\mathrm{j}$ indicates a particular dimension of the fuel cell geometry, Fig. 1.

The total net power (available for utilization) of the fuel cell is given by

$$
\tilde{W}_{n e t}=\tilde{W}-\tilde{W}_{p}
$$

where $\tilde{W}=\tilde{V}_{i} \tilde{I}$. The dimensionless pumping power, $\tilde{W}_{p}$, is given by

$$
\tilde{W}_{p}=\psi_{f} S_{f} \frac{\theta_{i}}{P_{i}} \Delta P_{1}+\psi_{o x} S_{o x} \frac{\theta_{7}}{P_{7}} \Delta P_{7}
$$

where $S_{i}=\frac{m_{r e f} T_{\infty} R_{i}}{V_{r e f} I_{r e f}}, i=f, o x$.

The mathematical model [11] allows for the calculation of the response of the fuel cell when its geometry and operating parameters change. The model accounts for temperature and pressure gradients and potential losses. An important step in thermodynamic optimization is the identification of realistic design constraints. The volume constraint is

$$
\xi_{\mathrm{x}} \xi_{\mathrm{y}} \xi_{\mathrm{z}}=1
$$

Additional constraints are the stoichiometric ratios in the fuel and oxidant channels, $\zeta_{1}$ and $\zeta_{7}$.

The objective function defined by Eq. (2) depends on the internal structure and the external shape of the fuel cell. The mathematical model allows the computation of the total net power of the fuel cell, $\tilde{W}_{n e t}$. This is possible to achieve as soon as the physical values listed in Table 1 are selected, and a set of geometric internal $\left(1=2 \xi_{b} / \xi_{x}+\sum_{i=1}^{7} \xi_{i} / \xi_{x}\right)$ and external $\left(\xi_{\mathrm{y}} / \xi_{\mathrm{x}}\right.$ and $\left.\xi_{\mathrm{z}} / \xi_{\mathrm{x}}\right)$ parameters are chosen for the overall system.

The maximum (theoretical) fuel cell efficiency is given by

$$
\eta_{i}=\frac{\Delta \tilde{G}_{3}+\Delta \tilde{G}_{5}}{\Delta \tilde{H}_{3}+\Delta \tilde{H}_{5}}
$$

The actual first-law efficiency of the fuel cell is

$$
\eta_{I}=E \frac{\tilde{W}}{\Delta \tilde{H}_{3}+\Delta \tilde{H}_{5}}
$$

where $\mathrm{E}=V_{\text {ref }} I_{\text {ref }} /\left(\dot{m}_{r e f} c_{p, f} T_{\infty}\right)$. The second-law efficiency is defined as the ratio of the actual electrical power

\begin{tabular}{|c|c|}
\hline $\begin{array}{l}\mathrm{B}=0.156[16] \\
\mathrm{c}_{\mathrm{p}, \mathrm{f}}=14.307 \mathrm{~kJ} \mathrm{~kg}^{-1} \mathrm{~K}^{-1} \\
\mathrm{c}_{\mathrm{p}, \mathrm{ox}}=0.918 \mathrm{~kJ} \mathrm{~kg}^{-1} \mathrm{~K}^{-1} \\
\mathrm{c}_{\mathrm{v}, \mathrm{f}}=10.183 \mathrm{~kJ} \mathrm{~kg}^{-1} \mathrm{~K}^{-1} \\
\mathrm{c}_{\mathrm{v}, \mathrm{ox}}=0.658 \mathrm{~kJ} \mathrm{~kg}^{-1} \mathrm{~K}^{-1} \\
\mathrm{c}_{\mathrm{s}, \mathrm{a}}=\mathrm{c}_{\mathrm{s}, \mathrm{c}}=0.133 \mathrm{~kJ} \mathrm{~kg}^{-1} \mathrm{~K}^{-1} \\
\left(\mathrm{i}_{0, \mathrm{a}}, \mathrm{i}_{0, \mathrm{c}}\right)=(0.0058,0.0019) \\
\mathrm{A} \mathrm{m}^{-2} \\
\mathrm{I}_{\mathrm{ref}}=1 \mathrm{~A} \\
\mathrm{k}_{\mathrm{f}}=0.182 \mathrm{~W} \mathrm{~m}^{-1} \mathrm{~K}^{-1} \\
\mathrm{k}_{\mathrm{ox}}=0.0267 \mathrm{~W} \mathrm{~m}^{-1} \mathrm{~K}^{-1} \\
\mathrm{k}_{\mathrm{p}}=0.1298 \mathrm{~W} \mathrm{~m}^{-1} \mathrm{~K}^{-1} \\
\mathrm{k}_{\mathrm{s}, \mathrm{a}}=\mathrm{k}_{\mathrm{s}, \mathrm{c}}=0.1 \mathrm{~W} \mathrm{~m}^{-1} \mathrm{~K}^{-1} \\
\mathrm{~K}_{2}, \mathrm{~K}_{6}=4.2 \times 10^{-14} \mathrm{~m}^{2} \\
\mathrm{~K}_{3}, \mathrm{~K}_{5}=4.2 \times 10^{-16} \mathrm{~m}^{2} \\
\dot{\mathrm{m}}_{\mathrm{ref}}=5 \times 10^{-2} \mathrm{~kg} \mathrm{~s}^{-1} \\
\mathrm{p}_{\mathrm{f}}=0.127 \mathrm{MPa} \\
\mathrm{p}_{\mathrm{ox}}=0.134 \mathrm{MPa} \\
\mathrm{p}_{\infty}=0.1 \mathrm{MPa} \\
\mathrm{q}=2.5 \\
\mathrm{R}_{\mathrm{f}}=4.157 \mathrm{~kJ} \mathrm{~kg}^{-1} \mathrm{~K}^{-1}\end{array}$ & $\begin{array}{l}\mathrm{R}_{\mathrm{ox}}=0.2598 \mathrm{~kJ} \mathrm{~kg}^{-1} \mathrm{~K}^{-1} \\
\mathrm{~T}_{\mathrm{f}}=\mathrm{T}_{\mathrm{ox}}=\mathrm{T}_{\infty}=\mathrm{T}_{0}=298.15 \mathrm{~K} \\
\mathrm{U}_{\mathrm{wi}}=50 \mathrm{~W} \mathrm{~m} \mathrm{~K}^{-1}, \mathrm{i}=1 \text { to } 7 \\
\mathrm{~V}_{\mathrm{ref}}=1 \mathrm{~V} \\
\mathrm{~V}_{\mathrm{T}, \mathrm{ref}}=10^{-4} \mathrm{~m}^{3} \\
\mathrm{y}=40 \mathrm{wt} \% \\
\alpha_{\mathrm{a}}=\alpha_{\mathrm{c}}=0.5 \\
\zeta_{1}, \zeta_{7}=2 \\
\theta_{0, i}=1(\mathrm{i}=1,7) \text {-initial val }\end{array}$ \\
\hline
\end{tabular}
to the reversible electrical power,

$$
\eta_{I I}=E \frac{\tilde{W}}{\Delta \tilde{G}_{3}+\Delta \tilde{G}_{5}}
$$

Table 1. Physical properties and initial values used in the single AMFC base case simulations

The net efficiency of the fuel cell is

$$
\eta_{n e t}=E \frac{\tilde{W}_{n e t}}{\Delta \tilde{H}_{3}+\Delta \tilde{H}_{5}}
$$

In a previous study, Vargas and Bejan [14] found the optimal distribution of the compartments shown in Fig. 1 for fuel cell maximum power under a volume constraint, for a liquid electrolyte alkaline fuel cell. However, the cross section area of the fuel cell was kept fixed in the process, therefore the external shape was not allowed to vary. A similar study was conducted to find the optimal distribution of the compartments shown in Fig. 1 for fuel cell maximum power under a volume constraint, for a single PEMFC [15] in which the external shape of the cell was allowed to vary. In this study, the constructal design seeks the optimal internal structure, length (or thickness), and external shape ( $\xi_{\mathrm{y}} / \xi_{\mathrm{x}}$ and $\left.\xi_{\mathrm{z}} / \xi_{\mathrm{x}}\right)$ that minimizes all flows resistances within the single AMFC based on the general configuration presented in Fig. 1, and according to the following brute force algorithm:

1. Establish realistic physical constraints for the optimization problem: fix total single AMFC dimensionless volume, $\tilde{V}_{T}$, assume a fuel cell square section, i.e., $\frac{\xi_{y}}{\xi_{x}}=\frac{\xi_{z}}{\xi_{x}}$, fix the ratios of anode thickness $\left(\mathrm{y}_{2}\right)$, cathode thickness $\left(\mathrm{y}_{6}\right)$ to total length $\left(\xi_{2} / \xi_{x}+\xi_{3} / \xi_{x}=y_{2}\right.$ and $\left.\xi_{5} / \xi_{x}+\xi_{6} / \xi_{x}=y_{6}\right)$, 
and the ratio of membrane thickness $\left(\mathrm{y}_{4}\right)$ to total length $\left(\xi_{4} / \xi_{x}=y_{4}\right)$, which comprise the ratio of the so called membrane-electrode-assembly (MEA) thickness to total length of the fuel cell $\mathrm{y}_{2}+\mathrm{y}_{4}+\mathrm{y}_{6}$.

2. Pick a range of variation for $y$ ( $\mathrm{KOH}$ mass fraction), divide in short intervals $\Delta y$ to be refined according to a given tolerance so that the obtained $\tilde{W}_{n e t, p, m m m}$ (the 3-way maximized AMFC net peak power) does not change, and select the lowest value for $y$.

3. Pick a range of variation for $\frac{\xi_{y}}{\xi_{x}}=\frac{\xi_{z}}{\xi_{x}}$, divide in short intervals $\Delta s_{\text {ext }}$ to be refined according to a given tolerance so that the obtained $\tilde{W}_{n e t, p, m m}$ (the 2-way maximized AMFC net peak power) does not change, and select the lowest value for $\frac{\xi_{y}}{\xi_{x}}=\frac{\xi_{z}}{\xi_{x}}$

4. Compute $\xi_{x}, \xi_{y}, \xi_{z}$.

5. For $\tilde{A}_{s}=\xi_{y} \xi_{z}$, perform the internal structure optimization: assume the anode and cathode with same thickness (symmetry) $\Rightarrow$ vary the thicknesses of the diffusion and reaction layers of the cathode and anode simultaneously reducing the problem to one degree of freedom, i.e., the ratio $\xi_{3} / \xi_{\mathrm{x}}=\xi_{5} / \xi_{\mathrm{x}}$ in a pre-specified range. For that, divide the domain in short intervals $\Delta s_{\text {int }}$ to be refined according to a given tolerance so that the obtained $\tilde{W}_{n e t, p, m}$ (the 1-way maximized AMFC net peak power) does not change.

6. As a result of item 5 , find $\left(\xi_{3} / \xi_{\mathrm{x}}=\xi_{5} / \xi_{\mathrm{x}}\right)_{\mathrm{opt}}$ that leads to the optimal internal structure that delivers a maximum value for $\tilde{W}_{n e t, p}$ (the AMFC net peak power observed for each ratio $\xi_{3} / \xi_{\mathrm{x}}=\xi_{5} / \xi_{\mathrm{x}}$ ), and return to step 4 until the entire $\frac{\xi_{3}}{\xi_{x}}=\frac{\xi_{5}}{\xi_{x}}$ pre-specified range is covered.

7. As a result of items 5 and 6 , obtain $\tilde{W}_{n e t, p, m}$, increment $\frac{\xi_{y}}{\xi_{x}}=\frac{\xi_{z}}{\xi_{x}}$ and return to step 3 until the entire $\frac{\xi_{y}}{\xi_{x}}=\frac{\xi_{z}}{\xi_{x}}$ pre-specified range is covered.

8. The result of the loop 3 to 7 is the optimized configuration of the single AMFC for the 2-way maximum net power density that is possible to be obtained in a constrained total volume, $V_{T}$, given by Eq. (31): $\left(\frac{\xi_{3}}{\xi_{x}}=\frac{\xi_{5}}{\xi_{x}}, \frac{\xi_{y}}{\xi_{x}}=\frac{\xi_{z}}{\xi_{x}}\right)_{\text {opt }} \Rightarrow \tilde{W}_{n e t, p, m m}$, for a specific $\mathrm{KOH}$ mass fraction in the electrolyte.

9. After obtaining $\tilde{W}_{n e t, p, m m}$, increment y and return to step 2 until the entire y pre-specified range is covered.

10. The result of the loop 2 to 9 is the optimized configuration of the single AMFC for the 3-way maximum net power density that is possible to be obtained in a constrained total volume, $V_{T}$, given by Eq. (31): $\left(\frac{\xi_{3}}{\xi_{x}}=\frac{\xi_{5}}{\xi_{x}}, \frac{\xi_{y}}{\xi_{x}}=\frac{\xi_{z}}{\xi_{x}}, y\right)_{o p t} \Rightarrow \tilde{W}_{n e t, p, m m m}$
In the optimization procedure the total electrode wetted area varies. Because the total volume is fixed, the solution to the optimization problem is given directly in terms of net power and current, instead of power and current densities.

\section{RESULTS AND DISCUSSION}

An experimental validation of the mathematical model was conducted previously using experimental data from a prototype of the single AMFC [11], in which the proposed alkaline membrane is composed by a cellulose based support embedded in an alkaline solution of water and potassium hydroxide [17]. Through the experiments, it was found that the single AMFC delivers maximum power output at $y=40$ wt. \% [11], which is a result of the effect of $\mathrm{KOH}$ concentration on the exchange current density that defines the activity of the electrodes, and strongly influences the fuel cell performance. Therefore, the following empirical correlations for platinum-carbon electrode sheets, type LT-250-EW, from BASF, with the load of $5 \mathrm{~g} / \mathrm{m}^{2}$ of $30 \mathrm{wt}$. \% Pt supported in Vulcan XC-72, were obtained by Sommer et al. [11], which were the electrodes used in the AMFC prototype [17]:

$$
\begin{aligned}
& i_{0, a}=-2.14 \times 10^{-7} y^{3}+1.53 \times 10^{-5} y^{2}-0.00019 y+0.00272 \\
& i_{0, c}=-4.35 \times 10^{-9} y^{4}+3.11 \times 10^{-7} y^{3}-5.16 \times 10^{-6} y^{2} \\
& +3.08 \times 10^{-5} y+0.00014
\end{aligned}
$$

In the calculations performed in this study, $i_{0, a}$ and $i_{0, a}$ were evaluated with Eqs. (9) and (10) to simulate and analyze the AMFC physical response under different geometric and operating conditions within their range of validity, i.e.,

$$
10 \text { wt. } \% \leq \mathrm{y} \leq 50 \text { wt. } \%
$$

The single AMFC geometry and volume constraint used in the simulations and optimization process is shown in Table 2. According to the optimization algorithm discussed in section 3 , for each investigated geometry, the net power is calculated by starting from open circuit $(\tilde{I}=0)$ and proceeding in increments of $\Delta \tilde{I}=1$ until the net power is zero, the limiting current level is reached, the anodic or cathodic potential are zero, or the maximum operating temperature is reached.

Table 2. AMFC geometry and volume constraint used in the optimization process

\begin{tabular}{|cc|}
\hline Dimensionless geometry/volume & Values \\
\hline$\xi_{1} / \xi_{x}=\xi_{7} / \xi_{x}$ & 0.05 \\
$\xi_{2} / \xi_{x}=\xi_{6} / \xi_{x}$ & 0.05 to 0.249 \\
$\xi_{3} / \xi_{x}=\xi_{5} / \xi_{x}$ & 0.001 to 0.2 \\
$\xi_{4} / \xi_{x}$ & 0.3 \\
$\xi_{8} / \xi_{x}=\xi_{9} / \xi_{x}$ & 0.05 \\
$\xi_{y} / \xi_{x}=\xi_{z} / \xi_{x}$ & $(20$ to 200$)$ \\
$\tilde{V}_{T}$ & $(0.5$ to 10$)$ \\
\hline
\end{tabular}

In the case presented in Fig. 2a, the simulation stopped when $\tilde{V}_{i, c}=0$. Under such selected operating conditions and 
geometry $\left(\xi_{y} / \xi_{x}=\xi_{z} / \xi_{x}=80\right)$, the AMFC did not reach the concentration polarization region where either $\tilde{V}_{e, a}$ or $\tilde{V}_{e, c}$ would approach zero. The net power curve exhibits a peak at $\tilde{I} \approx 250$, which is the point utilized to evaluate the single AMFC global performance, by balancing total electrical power produced with required pumping power to supply fuel and oxidant to the fuel cell. The peak net power, $\tilde{W}_{n e t, p}$, is maximized during the geometry optimization.

Figure $2 b$ shows that the ideal efficiency $\left(\eta_{i}\right)$ decreases as the current increases. This effect is due to the temperature increase in the anode and cathode reaction layers. The temperature increase is captured by the present model. The second law efficiency is equal to 1 (reversible operation - no losses) at open circuit ( $\tilde{I}=0)$, and decreases monotonically as the current increases. The net efficiency behavior shows the effect of increasing current and therefore pressure drop in the gas channels, i.e., the pumping power increases and the net power decreases, which would eventually reach a zero limit when $\tilde{W}_{n e t}=0$. For the geometry studied in Fig. 2 b, i.e., $\left(\xi_{y} / \xi_{x}=\xi_{z} / \xi_{x}=80\right)$, the first law efficiency is approximately equal to the net efficiency since pumping power is small compared to the electrical power produced by the AMFC, e.g., at the peak power when $\tilde{I} \approx 250$, $\tilde{W}=104.68$, and $\tilde{W}_{p}=6.84$, i.e., $\tilde{W}_{p}<<\tilde{W}$.

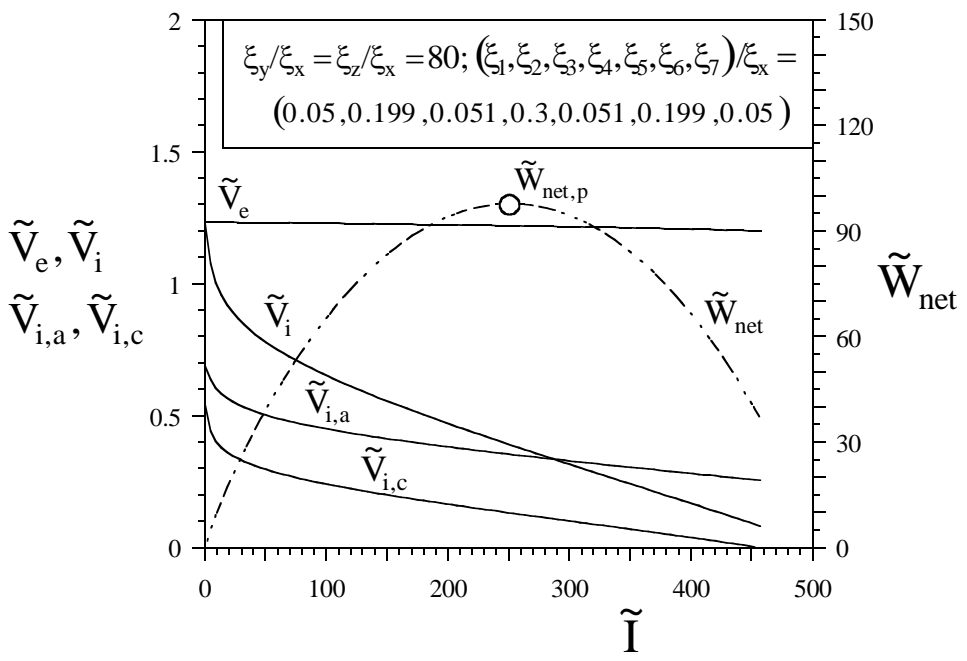

(a)

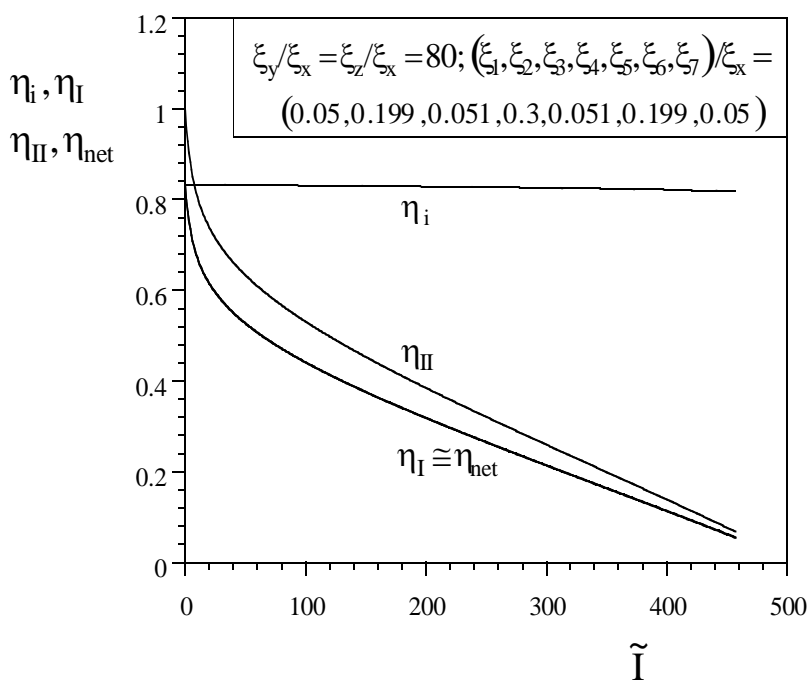

(b)

Figure 2. (a) Polarization and power, and (b) Efficiencies curves for one of the AMFC tested geometries.

The internal and external structure geometric parameters were varied seeking to reduce the irreversibilities of the AMFC to a minimum value. The values for $\Delta s_{\text {int }}, \Delta s_{\text {ext }}$, and $\Delta y$ were halved until $\tilde{W}_{n e t, p, m}, \tilde{W}_{n e t, p, m m}$, and $\tilde{W}_{n e t, p, m m m}$, 1-, 2-, and 3-way maximized peak net power output, respectively, did not change in two sequential refinements 
$(i$ and $\mathrm{i}+1)$, picking the less refined set of results [38], according to objective function relative error, as follows:

$$
\frac{\left|f_{i}-f_{i+1}\right|}{f_{i}} \leq \varepsilon
$$

in which, $\mathrm{f}$ is the objective function being maximized in the optimization process, i.e., the peak net power output, $\tilde{W}_{n e t, p}$, and $\varepsilon=0.01(1 \%)$ was the tolerance value assumed in this study.

Figure 3 illustrates the optimization of internal structure: the maximization of net power by varying $\xi_{3} / \xi_{x}=\xi_{5} / \xi_{x}$ subject to fixed $\mathrm{y}_{2}=\mathrm{y}_{6}=0.25$, which also means that the membrane-electrode-assembly (MEA) thickness is fixed, i.e., $\mathrm{y}_{2}+\mathrm{y}_{4}+\mathrm{y}_{6}=0.8$. The optimal allocation of thickness results from the trade-off between two effects: activation polarization losses and ohmic losses. As $\xi_{3} / \xi_{x}$ and $\xi_{5} / \xi_{x}$ increase, the electrode wetted areas increase and the activation losses decrease. On the other hand, the ohmic losses increase because the liquid electrolyte penetrates deeper into the electrodes and the reaction layer thickness increases, raising electrical resistance. The results of those trade-offs observed during internal geometry variation in the optimization process is investigated in Fig. 3 which shows peak net power maxima for a wide range of fuel cell external geometric aspect ratios $\left(20 \leq \xi_{y} / \xi_{x}=\xi_{z} / \xi_{x} \leq 200\right)$, and $\mathrm{y}=40$ wt. \%. The internal structure optimization was conducted for the range $0.001 \leq \xi_{3} / \xi_{x}=\xi_{5} / \xi_{x} \leq 0.2$. It is found that for each tested external aspect ratio there is a 1 -way maximized single AMFC net power output, $\tilde{W}_{n e t, p, m}$.

The 1-way maximized single AMFC net power output results show that there is indeed a second maximum with respect to the single AMFC external aspect ratio. However, the results of Fig. 3 were obtained for an alkaline membrane with $\mathrm{y}=40$ wt. $\%$. The effect of the electrolyte solution $\mathrm{KOH}$ mass fraction on performance is addressed next.

The 3-way maximized peak net power output, $\tilde{W}_{n e t, p, m m m}$, is found in Fig. 4 according to the algorithm described in section 4 . The numerical results confirm the robustness of the experimentally found optimal value $y \cong 40 \mathrm{wt}$. $\%$ for the entire tested ranges of internal and external single AMFC structure for maximum performance. The maximum is sharp, which highlights the importance of working with optimal $\mathrm{KOH}$ mass fraction in actual AMFC design.

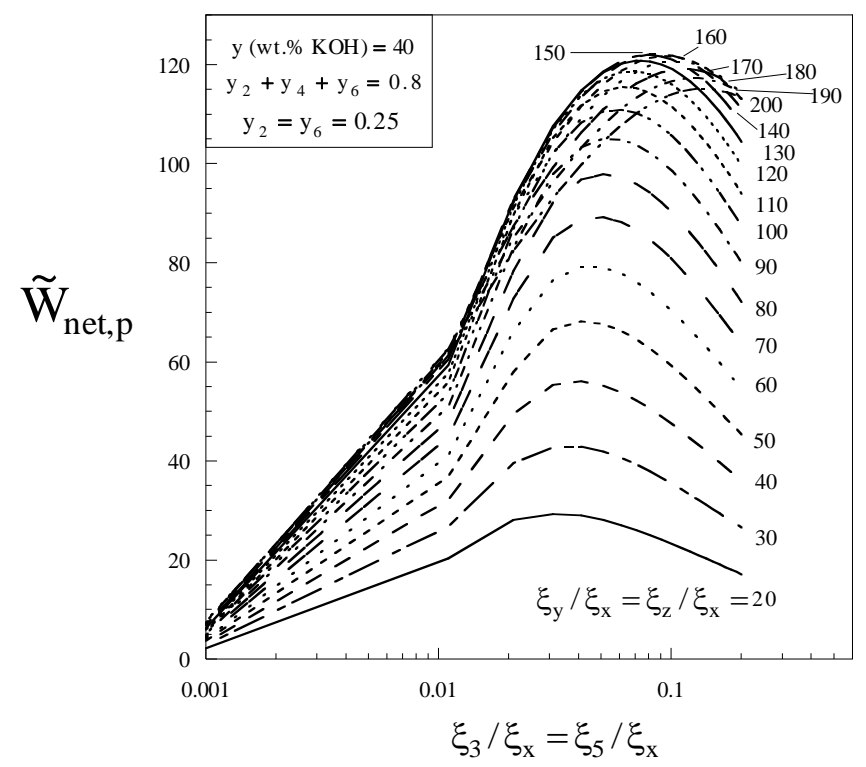

Figure 3. The AMFC internal structure optimization for obtaining the 1-way maximized peak net power output for several external shapes

The 3-way maximized single AMFC peak net power with respect to the electrolyte mass fraction, internal and external configurations increases monotonically as $\tilde{V}_{T}$ increases. The external aspect ratio also increases as $\tilde{V}_{T}$ increases. The results are presented in Fig. 5, from which the following correlations were obtained by curve fitting the calculated points (empty symbols):

$$
\begin{aligned}
& \left(\xi_{y} / \xi_{x}=\xi_{z} / \xi_{x}\right)_{o p t}=127.93 \tilde{V}_{T}^{0.20279} \\
& \tilde{W}_{\text {net }, p, \text { mmm }}=69.983 \tilde{V}_{T}^{0.6688}
\end{aligned}
$$




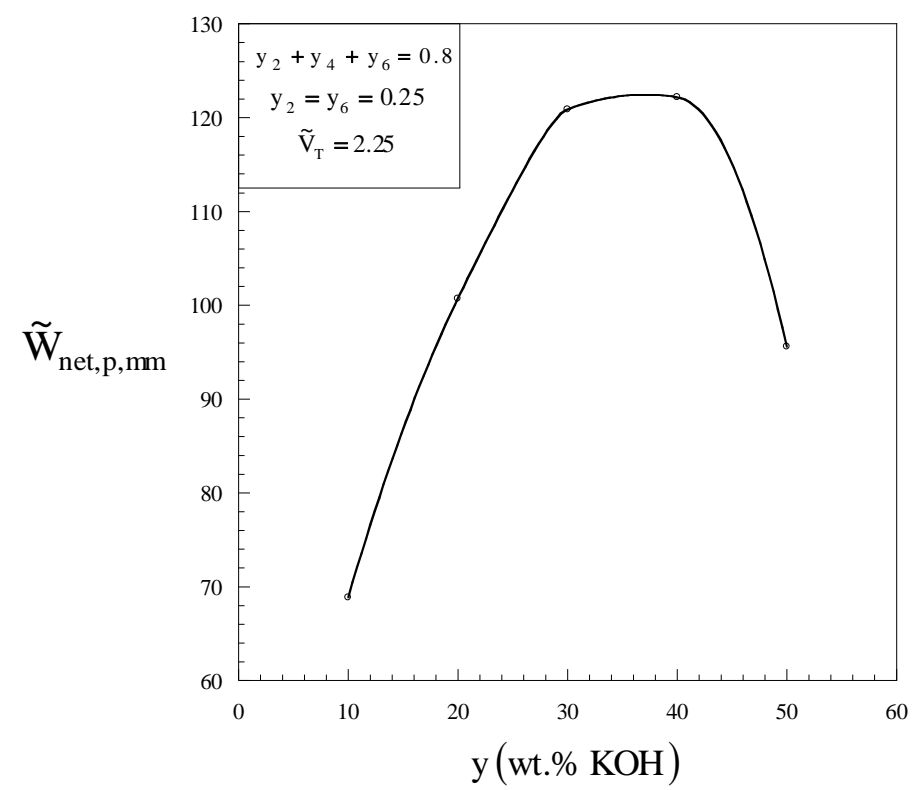

Figure 4. The 3-way maximization of the AMFC peak net power output with respect to electrolyte $\mathrm{KOH}$ mass fraction

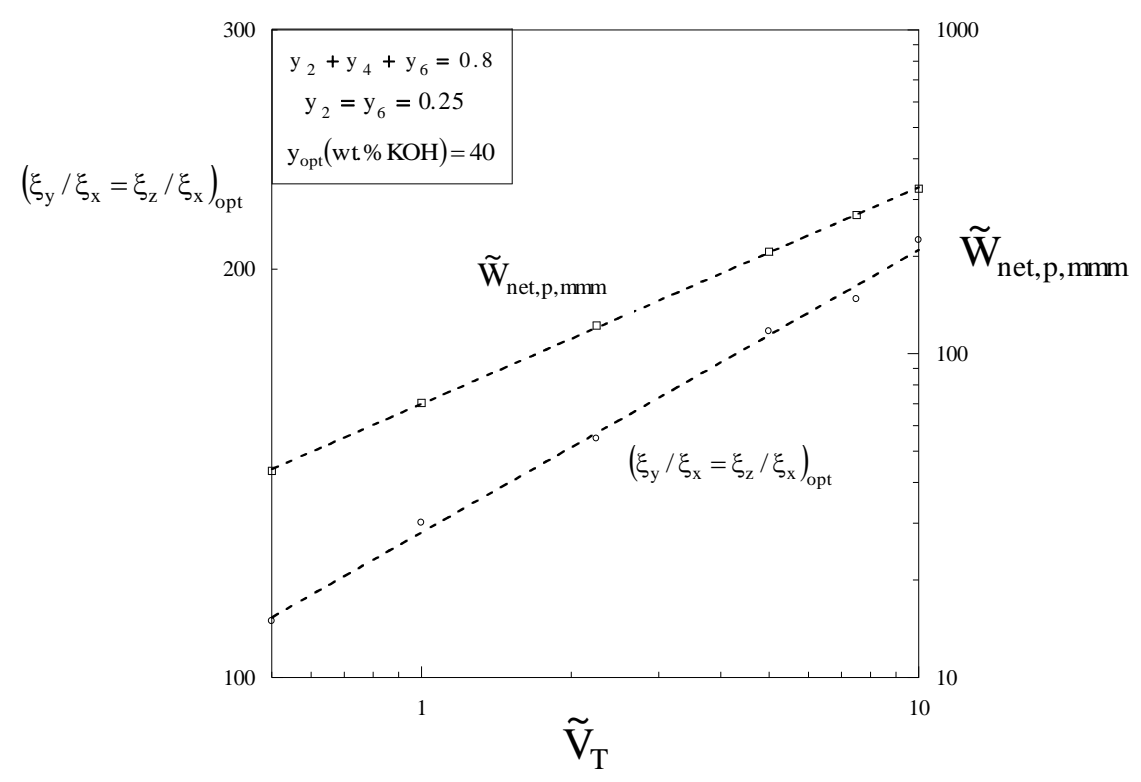

Figure 5. The 3-way maximized AMFC peak net power output and optimal external shape, with respect to dimensionless total volume

\section{CONCLUSIONS}

The problem of designing the flow structure of an alkaline membrane fuel cell (AMFC) for maximum net power output was investigated. It was shown that the optimal single AMFC internal and external structure results from minimizing overpotential losses, thermal and fluid flow resistances, i.e., constructal design [10]. The main conclusions of this study are summarized by:

1. The maxima numerically found are sharp, showing a net power output $600 \%$ variation within the tested range of AMFC external aspect ratios, highlighting the importance of finding the optimal AMFC parameters, no matter how complex the actual design might be;

2. It was clearly demonstrated that even for a single AMFC, gas supply causes pressure drops that induce considerable power consumption that need to be taken into account in fuel cell design;
3. In general, the flowfield should be designed to minimize pressure drop (reducing parasitic pump requirements), while providing adequate and evenly distributed mass transfer through the carbon diffusion layer to the catalyst surface for reaction, and

4. Since the AMFC model was previously experimentally validated [11], it is reasonable to state that the herein reported optimization results are accurate enough for single AMFC design, and the mathematical model could be used to proceed to the AMFC stack optimization level.

\section{ACKNOWLEDGMENT}

The National Council for Scientific and Technological Development, CNPq, Brazil, grant - 407198/2013-0. The Brazilian Ministry of Education - PDEE/CAPES. 


\section{REFERENCES}

1. Grove, W.R., "On voltaic series and the combination of gases by platinum," Philosophical Magazine and Journal of Science XIV, 127-130, 1839. DOI: 10.1080/14786443908649684.

2. O'Hayre, R., Cha, S.K., Colella, W., Prinz, F.B., Fuel Cell Fundamentals, New York: John Wiley \& Sons; 2006.

3. Gencoglu, M.T., Ural, Z., "Design of a PEM fuel cell system for residential application," Int $J$ Hydrogen Energy 34(12), 5242-5248, 2009. DOI: 10.1016/j.ijhydene.2008.09.038.

4. Kazempoor, P., Dorer, V., Weber, A., "Modelling and evaluation of building integrated SOFC systems," Int $J$ Hydrogen Energy 36(20), 13241-13249, 2011. DOI: 10.1016/j.ijhydene.2010.11.003.

5. Sammes, N.M., Boersma, R., "Small-scale fuel cells for residential applications," J Power Sources 86(1-2), 98110, 2000. DOI: $10.1016 / \mathrm{S} 0378-7753(99) 00415-2$.

6. Burchardt, T., Gonerec, P., Sanchez-Cortezon, E., Karichev, Z., Miners, J.H., "Alkaline fuel cells: contemporary advancement and limitations," Fuel $81: 2151-2155, \quad 2002$. DOI: $10.1016 /$ S00162361(02)00163-1.

7. Tewari, A., Sambhy, V., Macdonald, M.U., Sen, A., "Quantification of carbon dioxide poisoning in air breathing alkaline fuel cells," Journal of Power Sources 153:1-10, 2006. DOI: 10.1016/j.jpowsour.2005.03.192.

8. Secanell, M., Wishart, J., Dobson, P., "Computational design and optimization of fuel cells and fuel cell systems: a review," Journal of Power Sources 196, 3690-3704, 2011. DOI: 10.1016/j.jpowsour.2010.12.011.

9. Ang, S.M.C., Fraga, E.S., Brandon, N.P., Nouri, J., Samsatli, N.J., Daniel, J.L., "Fuel cell systems optimisation - Methods and strategies," Int J Hydrogen Energy 36, 14678-14703, 2011. DOI: $\underline{10.1016 / \text { j.ijhydene.2011.08.053. }}$.
10. Bejan, A., Shape and Structure, from Engineering to Nature, Cambridge, UK: Cambridge University Press; 2000.

11. Sommer, E.M., Martins, L.S., Vargas, J.V.C., Gardolinski, J.E.F.C., Ordonez, J.C., Marino, C.E.B., "Alkaline membrane fuel cell (AMFC) modeling and experimental validation," Journal of Power Sources 213, 16-30, 2012 . DOI: 10.1016/j.jpowsour.2012.03.089.

12. Vargas, J.V.C., Stanescu, G., Florea, R., Campos, M.C., "A numerical model to predict the thermal and psychrometric response of electronic packages," ASME Journal of Electronic Packaging 123(3), 200-10, 2001. DOI: $10.1115 / 1.1348337$.

13. Dilay, E., Vargas, J.V.C., Souza, J.A., Ordonez, J.C., Yang, S., Mariano, A.B., "A volume element model (VEM) for energy systems engineering," International Journal of Energy Research 39(1), 46-74, 2015. DOI: 10.1002/er.3209.

14. Vargas, J.V.C., Bejan, A., "Thermodynamic optimization of internal structure in a fuel cell," International Journal of Energy Research 28, 319-39, 2004. DOI: 10.1002/er.967.

15. Vargas, J.V.C., Ordonez, J.C., Bejan, A., "Constructal flow structure for a PEM fuel cell," International Journal of Heat and Mass Transfer 47, 4177-4193, 2004. DOI: $10.1016 /$ j.ijheatmasstransfer.2004.05.004.

16. Tarasevich, M.R., Sadkowski, A., Yeager, E., "In: Comprehensive Treatise of Electrochemistry," Convay, B.E., Bockris, J.O.M., Yeager, E., Khan, S.U.M., White, R.E., eds, Plenum, New York 7, 310-398, 1983.

17. Vargas, J.V.C., Gardolinski, J.E.F.C., Ordonez, J.C., Hovsapian, Z., "Method of producing electrical potential in fuel cell, involves providing electrolyte between anode and cathode respectively provided adjacent to anode and cathode diffusion layers, wetting electrolyte, and providing fuel and oxidizer," Patent No.: US2014087275-A1, 2014.

18. Editorial, "Journal of Heat Transfer editorial policy statement on numerical accuracy," ASME J. Heat Transfer 116, 797-798, 1994. 